\title{
PENGARUH SUMBER PERMODALAN DAN PEMBINAAN PEMBIAYAAN TERHADAP KEUNTUNGAN USAHA MIKRO, KECIL DAN MENENGAH ANGGOTA KOPERASI SYARIAH BAITUL QIRADH BAITURRAHMAN CABANG ULEE KARENG \\ (The Influence Of Capital Resources And Financing Of Profits Micro, Small And Medium Of Islamic Cooperation Baitul Qiradh Baiturrahman Members Branch Ulee Kareng)
}

\author{
Nuzulul Fikri ${ }^{1}$, Safrida $^{1}$, Romano $^{{ }^{*}}$ \\ ${ }^{1}$ Program Studi Agribisnis, Fakultas Pertanian, Universitas Syiah Kuala
}

\begin{abstract}
Abstrak - Modal adalah salah satu faktor produksi yang berperan penting untuk meningkatkan keuntungan. Pembinaan pembiayaan merupakan program untuk memantau perkembangan usaha mikro kecil dan menengah yang memperoleh modal pinjaman. Penelitian ini bertujuan untuk mengetahui pengaruh modal sendiri, modal pinjaman dan pembinaan pembiayaan terhadap keuntungan usaha mikro kecil dan menengah (UMKM) anggota Koperasi Syariah Baitul Qiradh Baiturrahman Cabang Ulee Kareng. Populasi dalam penelitian ini adalah UMKM anggota Koperasi Syariah Baitul Qiradh Baiturrahman yang menerima modal pinjaman dan pembinaan pembiayaan. Teknik pengambilan sampel dilakukan dengan metode simple random sampling. Besarnya sampel dalam penelitian ini adalah sebanyak 24 sampel. Metode analisis yang digunakan dalam penelitian ini adalah analisis regresi linear berganda. Hasil penelitian menunjukan bahwa modal sendiri dan modal pinjaman berpengaruh nyata terhadap keuntungan UMKM, sebaliknya pembinaan pembiayaan tidak berpengaruh nyata terhadap keuntungan UMKM.
\end{abstract}

Kata kunci: UMKM, Modal, Pembinaan Pembiayaan, Keuntungan

\begin{abstract}
Capital is one of the factors of production which is essential to improve profits. Development of financing a program to monitor the development of micro, small and medium enterprises that obtain capital loan. This study aims to determine the influence of their own capital, loan capital and development funding to benefit micro, small and medium enterprises (MSMEs) Islamic Cooperative Baitul Qiradh Baiturrahman members Branch Ulee Kareng. The population in this study is the MSMEs Islamic Cooperative Baitul Qiradh Baiturrahman members, who received loan capital and financing guidance. The sampling technique is done by simple random sampling method. The sample size in this study is as much as 24 samples. The analytical method used in this research is multiple linear regression analysis. The results showed that equity and loan capital significantly affect profits of MSMEs, fostering financing otherwise not significantly affect profits of MSMEs.
\end{abstract}

Keywords: MSMEs, Capital, Development Financing, Profit

\section{PENDAHULUAN}

Usaha Mikro Kecil Menengah (UMKM) yang merupakan penopang ekonomi daerah dan menjadi salah satu bagian terpenting dalam pembangunan perekonomian suatu negara, walaupun dilihat dari skala ekonominya yang tidak seberapa namun jumlah UMKM sangat besar dan dominan serta sumbangan yang diberikan selama ini baik untuk masyarakat maupun Negara. Peran penting tersebut telah mendorong banyak negara termasuk Indonesia untuk terus berupaya mengembangkan UMKM (La Ede, 2013). 
Usaha Mikro Kecil dan Menengah (UMKM) berperan penting dalam perekonomian Provinsi Aceh. Jumlah UMKM di Provinsi Aceh tahun 2015 mencapai 48.822 unit yang terdiri dari usaha mikro 33.596 unit, usaha kecil 14.241 unit dan usaha menengah 985 unit. Jumlah unit terbanyak UMKM adalah di Kota Banda Aceh yaitu 6.482 atau 13,2 \% dari jumlah UMKM di Provinsi Aceh.

Usaha Mikro Kecil dan Menengah seringkali dihadapkan pada masalah atau kendala. Menurut Badan Pusat Statistik, terdapat beberapa faktor kesulitan usaha kecil dan menengah seperti pada Tabel 1.

Tabel 1. Faktor Kesulitan Usaha Mikro Kecil dan Menengah

\begin{tabular}{|l|c|c|}
\hline \multicolumn{1}{|c|}{ Jenis Kesulitan Utama } & Aceh & Nasional \\
\hline Bahan Baku & $19,22 \%$ & $25,02 \%$ \\
\hline Pemasaran & $21,07 \%$ & $21,33 \%$ \\
\hline Modal & $51,99 \%$ & $38,35 \%$ \\
\hline BBM/Energi & $0,21 \%$ & $1,05 \%$ \\
\hline Transportasi & $0,92 \%$ & $1,23 \%$ \\
\hline Keterampilan & $2,72 \%$ & $2,64 \%$ \\
\hline Upah Buruh & $0,88 \%$ & $0,72 \%$ \\
\hline Lainnya & $2,99 \%$ & $9,66 \%$ \\
\hline Mengalami Kesulitan & $76,51 \%$ & $73,01 \%$ \\
\hline Tidak Mengalami kesulitan & $23,49 \%$ & $26,99 \%$ \\
\hline Jumlah & $100,00 \%$ & $100,00 \%$ \\
\hline
\end{tabular}

Sumber : BPS, 2015

Berdasarkan tabel diatas diketahui bahwa kesulitan mendasar yang paling menonjol dalam memulai dan mengembangkan usaha kecil dan menengah di Provinsi Aceh adalah modal yaitu 51,99 \%, lebih besar dibandingkan skala nasional yaitu 38,35\%. Sumber permodalan dalam usaha ada dua yaitu modal sendiri dan modal asing. Namun, seringkali modal sendiri dalam usaha tidak mencukupi, sehingga ketidakcukupan modal dapat membatasi aktivitas pelaku usaha mikro kecil dan menengah untuk mengembangkan usahanya guna mencapai tingkat keuntungan yang optimal.

Oleh karena itu, untuk mencukupi kekurangan modal, usaha mikro kecil dan menengah menambah jumlah modal baik itu dari Pemerintah, Lembaga Keuangan Perbankan atau Lembaga Keuangan Bukan Perbankan. Salah satu lembaga yang turut berperan dalam mengurangi masalah permodalan usaha mikro kecil dan menengah di Kota Banda Aceh adalah Koperasi Syariah Baitul Qiradh Baiturrahman pada salah satu cabang, yaitu cabang Ulee Kareng Kota Banda Aceh.

Menyadari tidak hanya modal yang menjadi masalah usaha mikro kecil dan menengah, Koperasi Syariah Baitul Qiradh Baiturrahman tidak hanya memberikan modal pinjaman, tetapi juga memberi pembinaan. Program pembinaan tersebut selain dari Koperasi Baitul Qiradh Baiturrahman juga didukung oleh Pemerintah dan Lembaga terkait seperti Kementerian Koperasi Usaha Kecil dan Menengah. Program - program pembinaan yang telah dilaksanakan diantaranya pengembangan usaha sektor rill koperasi, mikro housing, pengembangan SDM KUKM melalui pelatihan dan uji sertifikasi SKKNI bidang koperasi simpan pinjam, dan lain-lain. Untuk program pembinaan dari Koperasi Syariah Baitul Qiradh Baiturrahman yang masih aktif hingga sekarang yaitu pembinaan pembiayaan.

Adapun permasalahan dalam penelitian ini, yaitu: Bagaimana modal sendiri, modal pinjaman dan pembinaan pembiayaan terhadap keuntungan usaha mikro kecil dan menengah anggota Koperasi Syariah Baitul Qiradh Baiturrahman Cabang Ulee Kareng. 
Tujuan penelitian ini adalah, untuk mengetahui mengetahui pengaruh modal sendiri, modal pinjaman dan pembinaan pembiayaan terhadap keuntungan usaha mikro kecil dan menengah anggota Koperasi Syariah Baitul Qiradh Baiturrahman Cabang Ulee Kareng.

\section{METODE PENELITIAN}

Penelitian ini dilakukan pada Koperasi Syariah Baitul Qiradh Cabang Ulee kareng Kota Banda Aceh. Pemilihan lokasi dilakukan secara sengaja (Purposive) didasarkan atas pertimbangan bahwa Koperasi Syariah Baitul Qiradh Baiturrahman cabang Ulee Kareng telah membantu masalah permodalan usaha mikro kecil dan menengah di Kota Banda Aceh. Objek penelitian ini adalah usaha mikro kecil dan menengah anggota Koperasi Syariah Baitul Qiradh Baiturrahman cabang Ulee Kareng Kota Banda Aceh. Ruang lingkup penelitian terbatas pada pengaruh modal sendiri, modal pinjaman dan pembinaan pembiayaan terhadap keuntungan usaha mikro kecil dan menengah anggota Koperasi Syariah Baitul Qiradh Baiturrahman cabang Ulee Kareng.

Populasi yang digunakan dalam penelitian ini adalah usaha mikro kecil dan menengah anggota Koperasi Syariah Baitul Qiradh Baiturrahman cabang Ulee Kareng yang berjumlah 243 orang. Teknik pengambilan sampel yang digunakan dalam penelitian ini adalah simple random sampling. Menurut Arikunto (2010) jika jumlah populasinya kurang dari 100 orang, maka jumlah sampelnya diambil secara keseluruhan, tetapi jika populasinya lebih besar dari 100 orang, maka bisa diambil 10-15\% dari jumlah populasinya. Berdasarkan jumlah populasi yaitu 243 orang, maka sampel penelitian ini diambil 10\%, sehingga didapatkan jumlah sampel 24 orang yaitu sebagai pelaku usaha mikro kecil menengah.

Jenis data dalam penelitian ini terdiri dari dua. Pertama, data primer yaitu data yang diperoleh dari lapangan dengan metode pengumpulan pada penelitian ini adalah metode metode kuisioner, wawancara dan observasi. Kedua, data sekunder yaitu data yang berhubungan dengan penelitian yang tidak didapatkan di lapangan. Data diperoleh dari studi kepustakaan, internet dan laporan instansi terkait seperti Badan Pusat Statistik.

Untuk mengetahui pengaruh modal sendiri, modal pinjaman dan pembinaan pembiayaan terhadap keuntungan usaha mikro kecil dan menengah anggota Koperasi Syariah Baitul Qiradh Baiturrahman Cabang Ulee Kareng, digunakan metode analisis berikut:

\section{Uji Validitas}

Uji validitas digunakan untuk mengukur sah atau valid tidaknya suatu kuesioner. Suatu kuesioner dikatakan valid jika pertanyaan pada kuesioner mampu untuk mengungkapkan sesuatu yang akan diukur oleh kuesioner tersebut (Ghozali, 2011). Dengan mengacu pada kriteria sebagai berikut:

a. Jika $R_{\text {hitung }}>R_{\text {tabel }}$ maka butir atau variabel tersebut valid.

b. Jika $R_{\text {hitung }}<R_{\text {tabel }}$ maka butir atau variabel tersebut tidak valid.

\section{Uji Reliabilitas}

Uji reliabilitas merupakan alat untuk mengukur suatu kuesioner yang merupakan indikator dari variabel atau konstruk. Suatu kuesioner dikatakan reliabel atau handal jika jawaban seseorang terhadap pernyataan adalah konsisten atau stabil dari waktu ke waktu (Ghozali, 2011).

Pengujian reliabilitasnya digunakan uji statistic Cronbach Alpha. Suatun konstruk atau variabel dikatakan reliabel jika memberikan nilai Cronbach Alpha > 
0,60 (Ghozali, 2013). Uji Validitas dan Uji Reliabilitas dihitung dengan menggunakan program Statistical Package for Social Science (SPSS) versi 21.

\section{Analisis Regresi Linier Berganda}

Analisis ini digunakan untuk menguji pengaruh variabel bebas (modal sendiri, modal pinjaman dan pembinaan pembiayaan) terhadap variabel terikat (keuntungan), secara matematis sebagai berikut (Sarwono, 2013) :

$$
\mathbf{Y}=\mathbf{a}+\mathbf{b}_{1} \mathbf{X}_{1}+\mathbf{b}_{2} \mathbf{X}_{2}+\mathbf{b}_{3} \mathbf{X}_{3}+\mathbf{e}
$$

dimana :

$\mathrm{Y} \quad=$ keuntungan $(\mathrm{Rp})$

A $\quad=$ konstanta

$\mathrm{X}_{1} \quad=$ modal sendiri $(\mathrm{Rp})$

$\mathrm{X}_{2} \quad=$ modal pinjaman $(\mathrm{Rp})$

$\mathrm{X}_{3} \quad=$ pembinaan pembiayaan (Skor)

$b_{1} b_{2} b_{3}=$ koefisien regresi

$\mathrm{e} \quad=$ error term

\section{Pengujian Hipotesis}

Hipotesis pada penelitian ini adalah :

a. $\mathrm{H}_{\mathrm{o}}$ : Modal sendiri, modal pinjaman dan pembinaan tidak berpengaruh nyata terhadap keuntungan usaha kecil dan menengah

b. $\mathrm{H}_{\mathrm{a}}$ : Modal sendiri, modal pinjaman dan pembinaan berpengaruh terhadap nyata keuntungan usaha kecil dan menengah.

\section{Uji T}

Uji $\mathrm{T}$ digunakan untuk menguji pengaruh variabel bebas (modal sendiri, modal pinjaman dan pembinaan pembiayaan) secara parsial terhadap variabel terikat (keuntungan) usaha mikro kecil dan menengah pada tingkat kepercayaan 95\%, dengan keputusan sebagai berikut :

a. Jika $\mathrm{T}_{\text {hitung }} \leq \mathrm{T}_{\text {tabel }}$, maka Ho diterima, Ha ditolak

b. $\quad$ Jika $\mathrm{T}_{\text {hitung }} \geq \mathrm{T}_{\text {tabel}}$, maka Ho ditolak, Ha diterima

\section{Uji F}

Uji $\mathrm{T}$ digunakan untuk menguji pengaruh variabel bebas (modal sendiri, modal pinjaman dan pembinaan pembiayaan) secara parsial terhadap variabel terikat (keuntungan) usaha mikro kecil dan menengah pada tingkat kepercayaan 95\%, dengan keputusan sebagai berikut :

a. Jika $T_{\text {hitung }} \leq \mathrm{T}_{\text {tabel}}$, maka Ho diterima, Ha ditolak

b. Jika $\mathrm{T}_{\text {hitung }} \geq \mathrm{T}_{\text {tabel}}$, maka Ho ditolak, $\mathrm{H}_{\mathrm{a}}$ diterima

\section{Pengujian Koefisien Determinasi $\left(\mathbf{R}^{2}\right)$}

Koefisien determinasi $\left(\mathrm{R}^{2}\right)$ pada intinnya mengukur seberapa jauh kemampuan model dalam menerangkan variasi variabel dependen (Ghozali, 2011). Penelitian ini mengukur persentase variabel independen (X) terhadap variabel dependen (Y). Koefisien Determinasi, secara matematis sebagai berikut (Sudjana, 2009) : 


$$
\mathrm{Kd}=\left(\mathrm{r}^{2}\right) \times 100 \%
$$

dimana :

$\mathrm{Kd}=$ Koefisien determinasi

$\mathrm{r} \quad=$ Koefisien korelasi

\section{HASIL DAN PEMBAHASAN}

\section{Uji Validitas}

Uji validitas pada penelitian ini untuk menguji keabsahan pertanyaan variabel pembinaan pembiayaan (X3) oleh Koperasi Syariah Baitul Qiradh Baiturrahman dalam benrtuk skor. Berdasarkan hasil perhitungan validitas dengan Program Statistical Package for Social Science (SPSS) versi 21 diperoleh bahwa nilai $\mathrm{R}_{\text {hitung }}$ lebih besar daripada nilai $\mathrm{R}_{\text {tabel }}$ sehingga seluruh pertanyaan dinyatakan valid. Uraian validitas pertanyaan dapat dilihat pada Tabel 2.

Tabel 2. Hasil Uji Validitas

\begin{tabular}{|l|c|c|c|c|}
\hline No & Variabel & $\mathrm{R}_{\text {hitung }}$ & $\mathrm{R}_{\text {tabel }}$ & Keterangan \\
\hline 1 & $\mathrm{X}_{3.1}$ & 0,721 & 0,404 & Valid \\
\hline 2 & $\mathrm{X}_{3.2}$ & 0,610 & 0,404 & Valid \\
\hline 3 & $\mathrm{X}_{3.3}$ & 0,678 & 0,404 & Valid \\
\hline 4 & $\mathrm{X}_{3.4}$ & 0,722 & 0,404 & Valid \\
\hline 5 & $\mathrm{X}_{3.5}$ & 0,646 & 0,404 & Valid \\
\hline
\end{tabular}

Sumber : Data Primer (diolah) 2016

\section{Uji Reliabilitas}

Uji reliabilitas pada penelitian ini untuk menguji kehandanlan pertanyaan kuisioner variabel pembinaan pembiayaan (X3). Berdasarkan hasil uji reliabilitas diperoleh nilai cronbach alpha minimum di atas 0,60 yaitu 0,695 . Hal ini menunjukkan bahwa pertanyaan untuk mengukur pengaruh pembinaan pembiayaan terhadap keuntungan usaha mikro kecil dan menengah memiliki tingkat konsistensi dari waktu ke waktu.

\section{Analisis Regresi Linier Berganda}

Analisis ini untuk menguji pengaruh positif atau negatif dari variabel modal sendiri, modal pinjaman, dan pembinaan pembiayaan terhadap keuntungan. usaha mikro kecil dan menengah. Uraian hasil analisis regresi linear berganda dengan program Statistical Package for Social Science (SPSS) versi 21 dapat dilihat pada Tabel 3.

Tabel 3. Hasil Analisis Linear Berganda

\begin{tabular}{|l|l|c|c|c|}
\hline \multicolumn{1}{|c|}{ Variabel } & \multicolumn{1}{|c|}{$\beta$} & $\mathrm{T}_{\text {hitung }}$ & $\mathrm{T}_{\text {tabel }}$ & Sig. \\
\hline Konstanta & -1118238 & & & \\
\hline Modal Sendiri (X1) & 0,63 & 2,222 & 2.086 &, 038 \\
\hline Modal Pinjaman (X2) & 0,55 & 3,159 & 2.086 &, 005 \\
\hline Pembinaan Pembiayaan (X3) & 144570 &, 822 & 2.086 &, 421 \\
\hline
\end{tabular}

Sumber : Data Primer (diolah) 2016 
Berdasarkan tabel diatas, dapat dibuat persamaan regresi linier berganda dan uraian sebagai berikut:

$$
Y=-1118238+0,063 \times 1+0,055 X 2+144570 \times 3
$$

a. Konstanta sebesar -1118238 artinya apabila modal sendiri, modal pinjaman dan pembinaan pembiayaan sama dengan nol maka nilai Y sebesar -1118238 .

b. Apabila variabel modal sendiri (X1) mengalami peningkatan sebesar Rp.1000 akan meningkatkan variabel Y (keuntungan) UMKM sebesar Rp.630 dengan asumsi faktorfaktor lain tetap.

c. Apabila variabel modal pinjaman (X2) mengalami peningkatan sebesar Rp.1000 akan meningkatkan variabel Y (keuntungan) UMKM sebesar Rp.550 dengan asumsi faktorfaktor lain tetap.

d. Dengan adanya pembinaan pembiayaan (X3) maka akan terjadi peningkatan keuntungan (Y) UMKM sebesar Rp. 144570 dengan asumsi faktor-faktor lain tetap.

\section{Pengujian Hipotesis \\ Uji T}

Uji T digunakan untuk menguji pengaruh variabel modal sendiri, modal pinjaman dan pembinaan pembiayaan secara parsial terhadap variabel keuntungan usaha mikro kecil dan menengah anggota Koperasi Syariah Baitul Qiradh Baiturrahman Cabang Ulee Kareng.

Berdasarkan hasil uji $t$, nilai $\mathrm{T}_{\text {hitung }}$ variabel modal sendiri (X1) sebesar sebesar 2,222 pada tingkat kepercayaan 95\% dan $\mathrm{T}_{\text {tabel }}$ 2.086. Karena nilai $\mathrm{T}_{\text {hitung }}>\mathrm{T}_{\text {tabel }}$, maka terima Ha tolak Ho yang dapat diartikan bahwa modal sendiri berpengaruh nyata terhadap keuntungan. Hal ini mendukung hipotesis pertama yaitu modal sendiri berpengaruh nyata terhadap keuntungan usaha mikro kecil dan menengah anggota Koperasi Syariah Baitul Qiradh Baiturrahman Cabang Ulee Kareng.

Hasil penelitian ini sesuai dengan penelitian oleh Harahap (2005) menyatakan bahwa modal sendiri berpengaruh nyata terhadap peningkatan pendapatan debitur. PT. Bank Bukopin Cabang Medan. Hal ini terlihat dari nilai $\mathrm{T}_{\text {hitung }}$ sebesar 3,089 pada tingkat kepercayaan $95 \%$ dan derajat kebebasan 27 , diperoleh $\mathrm{T}_{\text {tabel }} 2,052$.

Nilai $\mathrm{T}_{\text {hitung }}$ variabel modal pinjaman (X1)sebesar 3,159 dan $\mathrm{T}_{\text {tabel }}$ 2.086. Karena nilai $\mathrm{T}_{\text {hitung }}>\mathrm{T}_{\text {tabel }}$, maka terima Ha tolak Ho yang dapat diartikan bahwa modal pinjaman berpengaruh nyata terhadap keuntungan. Hal ini mendukung hipotesis kedua yaitu modal pinjaman berpengaruh nyata terhadap keuntungan usaha mikro kecil dan menengah anggota Koperasi Syariah Baitul Qiradh Baiturahman Cabang Ulee Kareng

Hasil penelitian ini sesuai dengan penelitian Akbar dkk (2013) menyatakan bahwa tambahan modal melalui program pinjaman bergulir Program Nasional Pemberdayaan Masyarakat Mandiri Perkotaan di Kelurahan Tangkerang Utara Kecamatan Bukit Raya Pekanbaru , berpengaruh nyata terhadap pendapatan usaha kecil di Kelurahan Tangkerang Utara Kecamatan Bukit Raya Pekanbaru.

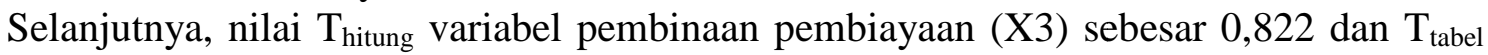
2.086. Karena nilai $\mathrm{T}_{\text {hitung }}<\mathrm{T}_{\text {tabel, }}$ maka terima Ho tolak Ha yang dapat diartikan bahwa pembinaan pembiayaan tidak berpengaruh nyata terhadap keuntungan. Hal ini disebabkan oleh belum maksimalnya kinerja pembinaan pembiayaan oleh Koperasi Syariah Baitul Qiradh Baiturrahman cabang Ulee Kareng dan juga kebutuhan pembinaan untuk meningkatkan keuntungan usaha mikro kecil dan menengah tidak hanya sebatas pembinaan pembiayaan saja atau masih ada yang belum terpenuhi. Menurut Peraturan Pemerintah, pembinaan usaha 
terdiri dari bidang produksi dan pengolahan, bidang pemasaran, bidang sumber daya manusia dan bidang desain teknologi.

Seperti halnya pada penelitian Suharyadi (2013) bahwa terdapat perbedaan yang signifikan pada produksi dan pendapatan UKM perikanan sesudah mengikuti program pembinaan oleh Dinas Kelautan dan Perikanan Provinsi Sumatera Utara. Dengan demikian bahwa program pembinaan oleh Dinas Kelautan dan Perikanan Provinsi Sumatera Utara terhadap UKM sub sektor perikanan memberikan dampak positif terhadap produksi dan pendapatan UKM. Bentuk-bentuk pembinaan yang diberikan antara lain di bidang produksi dan pengolahan, bidang pemasaran, bidang sumber daya manusia dan bidang desain teknologi. Sehingga pembinaan usaha mikro kecil menengah yang dimaksudkan oleh Pemerintah telah terpenuhi. Sedangkan pembinaan yang dilakukan oleh Koperasi Syariah Baitul Qiradh Baiturrahman cabang Ulee Kareng hanya sebatas pembinaan pembiayaan atau dengan tujuan manajerial keuangan dan mencegah penyimpangan modal pinjaman. Pembinaan tersebut tergolong dalam bidang sumber daya manusia.

\section{Uji F}

Uji F untuk menguji pengaruh modal sendiri, modal pinjaman dan pembinaan terhadap keuntungan usaha mikro kecil dan menengah anggota Koperasi Syariah Baitul Qiradh Baiturahman Cabang Ulee Kareng secara serempak. Uraian hasil uji F dapat dilihat pada Tabel 4.

Tabel 4. Hasil Uji F

\begin{tabular}{|l|c|c|c|c|}
\hline \multicolumn{1}{|c|}{ Model } & Df & $\mathrm{F}_{\text {hitung }}$ & $\mathrm{F}_{\text {tabel }}$ & Sig. \\
\hline Regresi & 3 & 7,276 & 3,07 & $0,002^{\mathrm{b}}$ \\
\hline Sisa & 20 & & & \\
\hline Total & 23 & & & \\
\hline
\end{tabular}

Sumber : Data Primer (diolah) 2016

Hasil analisis menujukkan nilai $F_{\text {hitung }}$ sebesar 7,276 dan $F_{\text {tabel }} 3,07$. Karena nilai $F_{\text {hitung }}>$ $\mathrm{F}_{\text {tabel }}$ maka terima Ha tolak Ho. Hal ini mendukung hipotesis keempat yaitu modal sendiri, modal pinjaman dan pembinaan pembiayaan secara serempak berpengaruh nyata terhadap terhadap keuntungan usaha mikro kecil dan menengah anggota Koperasi Syariah Baitul Qiradh Baiturahman Cabang Ulee Kareng

\section{Pengujian Koefisien Determinasi $\left(\mathbf{R}^{2}\right)$}

Uji koefisien determinasi untuk menguji seberapa besar pengaruh variabel modal sendiri, modal pinjaman dan pembinaan pembiayaan terhadap keuntungan usaha mikro kecil dan menengah. Berdasarkan hasil uji koefisien determinasi, diperoleh nilai adjusted $R$ square sebesar 0,522. Hal ini menunjukkan bahwa modal sendiri, modal pinjaman dan pembinaan pembiayaan berpengaruh terhadap keuntungan $52,2 \%$ dan sisanya 47,8\% dijelaskan oleh variabel di luar penelitian.

\section{KESIMPULAN DAN SARAN}

Modal sendiri dan modal pinjaman berpengaruh nyata terhadap keuntungan usaha mikro kecil dan menengah anggota Koperasi Syariah Baitul Qiradh Baiturrahman cabang Ulee Kareng. Sedangkan, pembinaan pembiayaan tidak berpengaruh nyata terhadap keuntungan usaha mikro kecil dan menengah anggota Koperasi Syariah Baitul Qiradh Baiturrahman cabang Ulee Kareng. Modal sendiri, modal pinjaman dan pembinaan secara serempak 
berpengaruh nyata terhadap keuntungan usaha mikro kecil dan menengah anggota Koperasi Syariah Baitul Qiradh Baiturrahman cabang Ulee Kareng.

Disarankan kepada Koperasi Syariah Baitul Qiradh Baiturrahman Cabang Ulee Kareng agar dapat menambah pembinaan selain pembinaan pembiayaan. Sehingga kebutuhan pembinaan untuk usaha mikro kecil dan menengah tercukupi, baik itu dari Koperasi Syariah Baitul Qiradh Baiturrahman sendiri atau bekerja sama dengan pemerintah dan instansi terkait.

\section{DAFTAR PUSTAKA}

Akbar, Rahmat, Caska dan Sri Kartikowati. 2013. Pengaruh Pemberian Kredit Modal Usaha Program Nasional Pemberdayaan Masyarakat Mandiri Perkotaan (Pnpm Mp) Terhadap Pendapatan Usaha Kecil Di Kelurahan Tangkerang Utara Kecamatan Bukit Raya Pekanbaru. Jurnal. Universitas Riau.

Arikunto, S. 2010. Prosedur penelitian : Suatu Pendekatan Praktik. (Edisi Revisi). Rineka Cipta. Jakarta.

Badan Pusat Statistik. 2015. Statistik Industri Mikro dan Kecil Provinsi Aceh 2014. BPS Provinsi Aceh. Aceh.

Ghozali, Imam . 2011. Aplikasi Analisis Multivariate dengan Program SPSS. BP Universitas Diponegoro. Semarang.

2013. Aplikasi Analisis Multivariat dengan Program IBM SPSS 21. Edisi 7. Penerbit Universitas Diponegoro. Semarang.

Harahap, Marleni Sari. 2005. Peranan Kredit UKM Terhadap Peningkatan Pendapatan Debitur Pada PT. Bank Bukopin Cabang Medan. Skripsi. Universitas Sumatera Utara.

La Ede, Usman Saleh. 2013. Analisis Pengaruh Locus Of Control Terhadap Strategi Operasional Dan Kinerja Umkm Dengan Lingkungan Sebagai Variabel Moderator.Skripsi. Universitas Hasanuddin Makasar.

Sarwono, Jonathan. 2013. 12 Jurus Ampuh SPSS untuk Riset Skripsi. PT Elex Media Komputindo. Jakarta.

Sudjana, Nana. 2009. Dasar-dasar Proses Belajar Mengajar. Sinar Baru Algesindo. Bandung.

Suharyadi, Erlina dan Supriyadi. 2013. Hubungan Antara Pelaksanaan Program Pembinaan Usaha Kecil Menengah Sub Sektor Perikanan di Wilayah Pesisir Dengan Tingkat Produksi Perikanan Provinsi Sumatera Utara. Jurnal Ekonom, Vol 16, No 3, Juli 2013. Universitas Sumatera Utara. 